\title{
Erratum to: Trophic ecology of Mnemiopsis leidyi in the southern North Sea: a biomarker approach
}

Lies Vansteenbrugge ${ }^{1,2} \cdot$ Kris Hostens $^{1} \cdot$ Brecht Vanhove $^{2} \cdot$ Annelies De Backer $^{1} \cdot$ Laurence De Clippele ${ }^{2} \cdot$ Marleen De Troch $^{2}$

Published online: 18 August 2016

C) Springer-Verlag Berlin Heidelberg 2016

\section{Erratum to: Mar Biol (2016) 163:25 \\ DOI 10.1007/s00227-015-2800-z}

Unfortunately, one of the author names in the reference was missed out in the original publication. The correct reference is provided here.

\section{Reference}

Anninsky BE, Finenko GA, Abolmasova GI, Hubareva ES, Svetlichny LS, Bat L, Kideys AE (2005) Effect of starvation on the biochemical compositions and respiration rates of ctenophores Mnemiopsis leidyi and Beroe ovata in the Black Sea. J Mar Biol Assoc UK 85:549-561

The online version of the original article can be found under doi:10.1007/s00227-015-2800-z.

Lies Vansteenbrugge

lies.vansteenbrugge@ilvo.vlaanderen.be

1 Bio-environmental Research, Aquatic Environment and Quality, Animal Sciences Unit, Institute for Agricultural and Fisheries Research (ILVO), Ankerstraat 1, 8400 Ostend, Belgium

2 Marine Biology, Biology Department, Faculty of Sciences, Ghent University (UGent), Krijgslaan 281 - S8, 9000 Ghent, Belgium 